\title{
Revision of Pseudoparicana (Hemiptera: Fulgoromorpha: Tropiduchidae) with description of a new species
}

\author{
Rong-Rong WANG ${ }^{1}$, IGOR MALENOVSKÝ ${ }^{2}$, AI-PING LIANG $^{1 *}$ and THIERry BOURGOIN ${ }^{3}$ \\ ${ }^{1}$ Key Laboratory of Zoological Systematics and Evolution, Institute of Zoology, Chinese Academy of Sciences, 1 Beichen West \\ Road, Chaoyang District, Beijing 100101, P.R. China; e-mails: wangrr_2008@163.com; liangap@ioz.ac.cn \\ ${ }^{2}$ Department of Entomology, Moravian Museum, Hviezdoslavova 29a, CZ-627 00 Brno, Czech Republic; \\ e-mail: imalenovsky@mzm.cz
}

${ }^{3}$ Département Systématique et Evolution, UMR 7205, MNHN-CNRS, Muséum National d'Histoire Naturelle, CP50, 45 rue Buffon, F-75005 Paris, France; e-mail: bourgoin@mnhn.fr

Key words. Morphology, taxonomy, Fulgoromorpha, Tropiduchidae, Pseudoparicana, genitalia asymmetry, Australasian Region

\begin{abstract}
The planthopper genus Pseudoparicana Melichar, 1914 is revised. Three previously known species, P. curvifera (Distant, 1907), P. sanguinifrons Muir, 1931 and P. tepida Melichar, 1914 are re-described and P. analoga Wang \& Malenovský sp. n. is described as new. Lectotypes are designated for $P$. curvifera and $P$. tepida. An identification key and illustrations of diagnostic characters, including male and female genitalia, are provided for all taxa and the systematic position of this genus and the asymmetry of the genitalia of the species are briefly discussed. As far as known, the distribution of Pseudoparicana is restricted to New Guinea and the Aru Islands.
\end{abstract}

\section{INTRODUCTION}

The planthopper genus Pseudoparicana (Hemiptera: Fulgoromorpha: Tropiduchidae) was established by Melichar (1914) for Paricana curvifera Distant, 1907 and Pseudoparicana tepida Melichar, 1914. Muir (1931) added a third species, $P$. sanguinifrons Muir, 1931. The genus has been recorded from Indonesia (Aru Islands) and New Guinea (Melichar, 1914; Muir, 1931). Unfortunately, the original descriptions of all three species lack illustrations and clear diagnostic information, particularly on the morphology of the male and female genitalia, which are crucial for their reliable identification. Moreover, Melichar's drawings (1914) of a dorsal view of the head and fore wing of $P$. tepida are inaccurate. Pseudoparicana was included in the tribe Paricanini by Melichar (1914) but transferred to the tribe Tropiduchini by Fennah (1982). Members of the Tropiduchini mainly occur in the Oriental and Afrotropical regions, including the western Pacific (Bourgoin, 2012).

Specimens of Pseudoparicana are rare in collections. While sorting and identifying Tropiduchidae in material from the California Academy of Sciences, San Francisco and the Moravian Museum, Brno, we found a new species of Pseudoparicana collected in Papua New Guinea. This new species and a revision of the type material of the previously described species enabled us to re-describe the genus and for the first time describe in detail with illustrations the male and female genitalia. We also provide a key for identification of the four currently known species and additional illustrations of the habitus, head, pronotum and wings. According to Article 74 of ICZN (1999), lec- totypes for $P$. curvifera and $P$. tepida are designated to stabilize the nomenclature in the genus.

\section{MATERIAL AND METHODS}

Dry-mounted specimens were used for the descriptions and illustrations. External morphology was observed under a stereoscopic microscope, measurements were made with an ocular micrometer. To examine male and female genitalia, abdomens were removed and macerated in $10 \% \mathrm{KOH}$ overnight. Precise dissections and cleaning of genital structures were finished in distilled water. Female ectodermal genital ducts were stained with Chlorazol black E (Bourgoin, 1993). Final observations and drawings were made in glycerine under a compound microscope. Photographs of habitus were taken with a Nikon Coolpix 5400 digital camera or with a Leica DFC 295 digital camera associated with a Leica Z16 APO macroscope. The digital images were then imported into Adobe Photoshop 8.0 for labelling and plate composition. Line figures were drawn with the aid of a camera lucida mounted on a Zeiss Stemi SV-11 stereomicroscope or on an Olympus BX41 compound microscope.

The specimens studied in the course of this work are deposited in the Natural History Museum, London, UK (BMNH), the California Academy of Sciences, San Francisco, California, USA (CAS), the Moravian Museum, Brno, Czech Republic (MMBC) and the Bavarian State Collection of Zoology, Munich, Germany (ZSM). Morphological terminology follows that of Bourgoin \& Huang (1990) and Bourgoin (1993) for male and female genitalia, respectively, and Bourgoin (1997) for tegmina.

\section{RESULTS \\ Pseudoparicana Melichar \\ Pseudoparicana Melichar, 1914: 111; Metcalf, 1954: 134.}

\footnotetext{
* Corresponding author; e-mail: liangap@ioz.ac.cn
} 


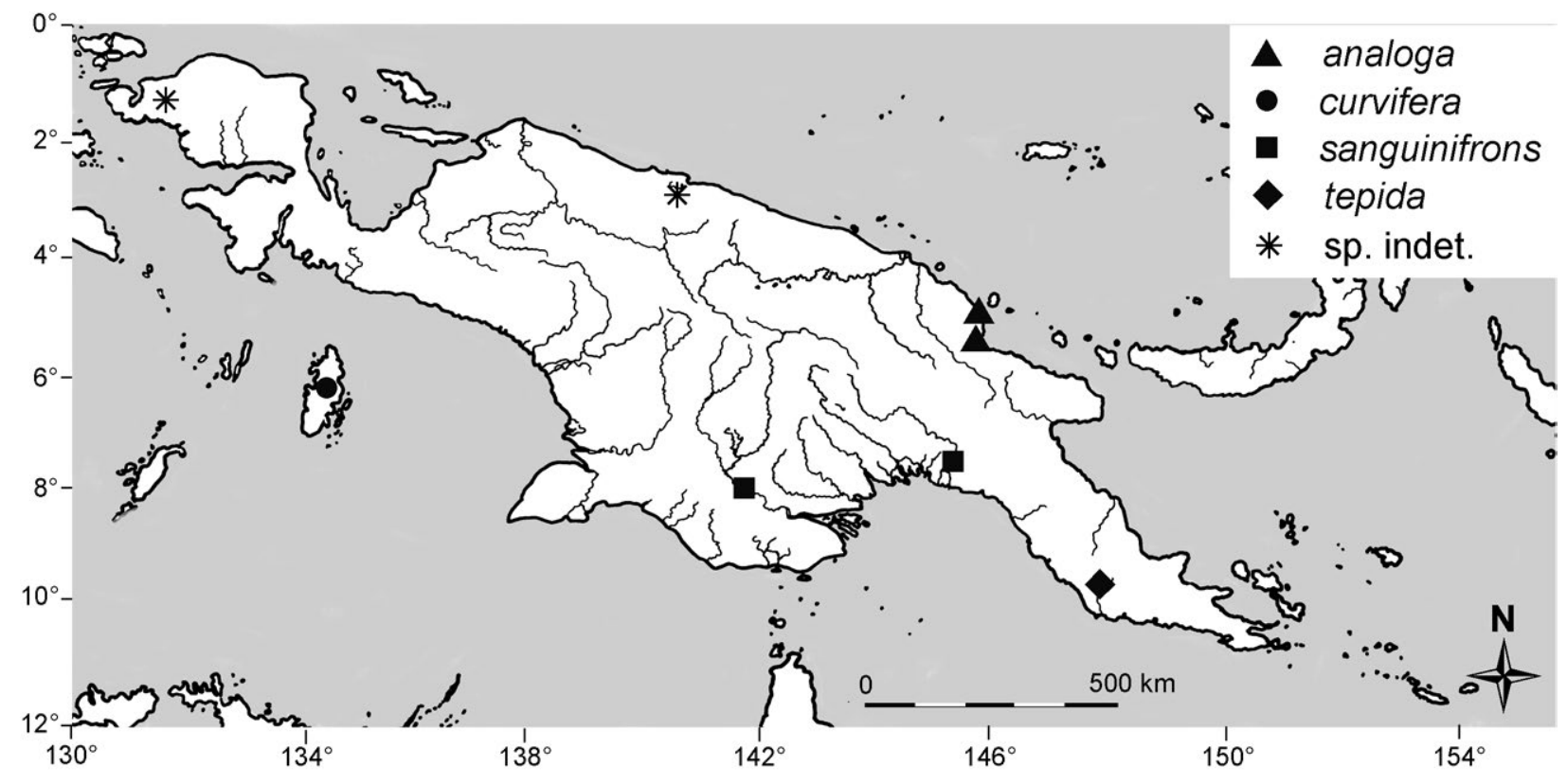

Fig. 1. Geographical distribution of Pseudoparicana species in New Guinea and adjacent islands.

Type species. Paricana curvifera Distant, 1907, by original designation.

Included species. P. curvifera (Distant, 1907), P. tepida Melichar, 1914, P. sanguinifrons Muir, 1931 and $P$. analoga Wang \& Malenovský sp. n.

\section{Description}

Coloration. General colour of body is straw-colored to brownish yellow. Fore wings (Figs 2A-F, 3D) hyaline, marked with two more or less narrow transverse brown bands, one situated sub-basally, the other along the nodal line (in P. tepida, band along nodal line is indistinct).

Head and thorax. Head in dorsal view (Figs $2 \mathrm{~A}-\mathrm{C}, \mathrm{E}$, 3B) short and broad, produced in front of eyes approximately for a half the length of an eye, with apex broadly convex; in lateral view (Figs 2D, F, 3C) evenly and broadly rounded down to base of frons, vertex and frons not separated, lateral carinae continuous. Vertex (Figs $2 \mathrm{~A}-\mathrm{C}, \mathrm{E}, 3 \mathrm{~B}$ ) about 2.75 times as broad at base than long at midline, and slightly longer than the length of pronotum at midline $(1.25: 1)$; lateral margins ridged and gently convex; posterior margin ridged and concave; anterior part of vertex smoothly convex; posterior part of vertex distinctly depressed, lateral margins of depression incurving anteriorly and meeting medially to form a nearly straight or slightly convex line; vertex without median carina. Frons (Figs 2G-J, 3A) longer than broad, widest in lower portion, usually medially swollen and shiny, disc between median swollen portion and lateral carinae depressed in shallow grooves on each side, converging down to clypeus (in P. tepida, frons is regularly convex, lacking median swelling and depressed grooves); lateral margins of frons distinctly convex adjacent to clypeus; frontoclypeal suture obtusely angled, concave. Clypeus convex, medially swollen in continuation with the median swollen area on frons and lacks lateral carinae. Labium long, reaching between hind coxae, apical segment distinctly longer than broad. Compound eyes oval. Lateral ocelli distinct. Antenna with a short ring-like scape; pedicel cylindrical, covered with many micro-setae extending to base of pedicel.

Pronotum (Figs 2A-C, E, 3B) about as long as one-fifth length of mesonotum in midline; median carina distinctly ridged, lateral carinae converging anteriorly; disc arched anteriorly, deeply depressed between median and lateral carinae, with an impression on each side; posterior margin broadly ridged, excavated in obtuse angle. Mesonotum (Figs 2A-C, E, 3B) tricarinate, median carina straight, reaching to transverse suture; sides of the posterior half of the lateral carinae are parallel, curved in anterior half, uniting with median carina; pronotum and mesonotum together medially about 4.8 times as long as median length of vertex. Fore wings (Figs 2A-C, E, 3D) hyaline, veins prominent, covered with short setae ventrally (veins in basal area of corium not covered with setae); corium without granulation, costal cell without cross veins; RA forks twice; nodal line includes $\mathrm{Sc}+\mathrm{R}$ fork, $\mathrm{M}_{1+2}-\mathrm{M}_{3+4}$ fork and $\mathrm{CuA}$ fork; CuA forked basad of fork in stem $\mathrm{M} ; \mathrm{CuA}_{1}$ bifurcated in distal $1 / 4$ of fore wing, with 2 terminals; $\mathrm{CuA}_{2}$ basally curved, then fused with post-claval margin postnodally; sometimes apically re-emerging to connect icu before ending in the postclaval margin (Fig. 3D); $\mathrm{A}_{1}$ short, running parallel to internal-postero-claval margin before uniting with $\mathrm{A}_{2}$ on the basal $1 / 3$ of clavus; corium with 6 sub-apical and 12 apical cells, sub-apical cells distinctly longer than apical cells. Hind wings (Fig. 3E) hyaline, elongate, not wider than tegmen, with anal lobe wide, posterior margin strongly sinuate; Sc+RA single, RP with two branches, $r-m$ veinlet single, $M$ with three terminals: branch $M_{1+2}$ forked and $\mathrm{M}_{3+4}$ single, $\mathrm{CuA}$ with three terminals: $\mathrm{CuA}_{1}$ single and $\mathrm{CuA}_{2}$ forked, single veinlets m-cua and cua-cup present, $\mathrm{CuP}$ with single terminal, Pcu forked, $\mathrm{A}_{1}$ 

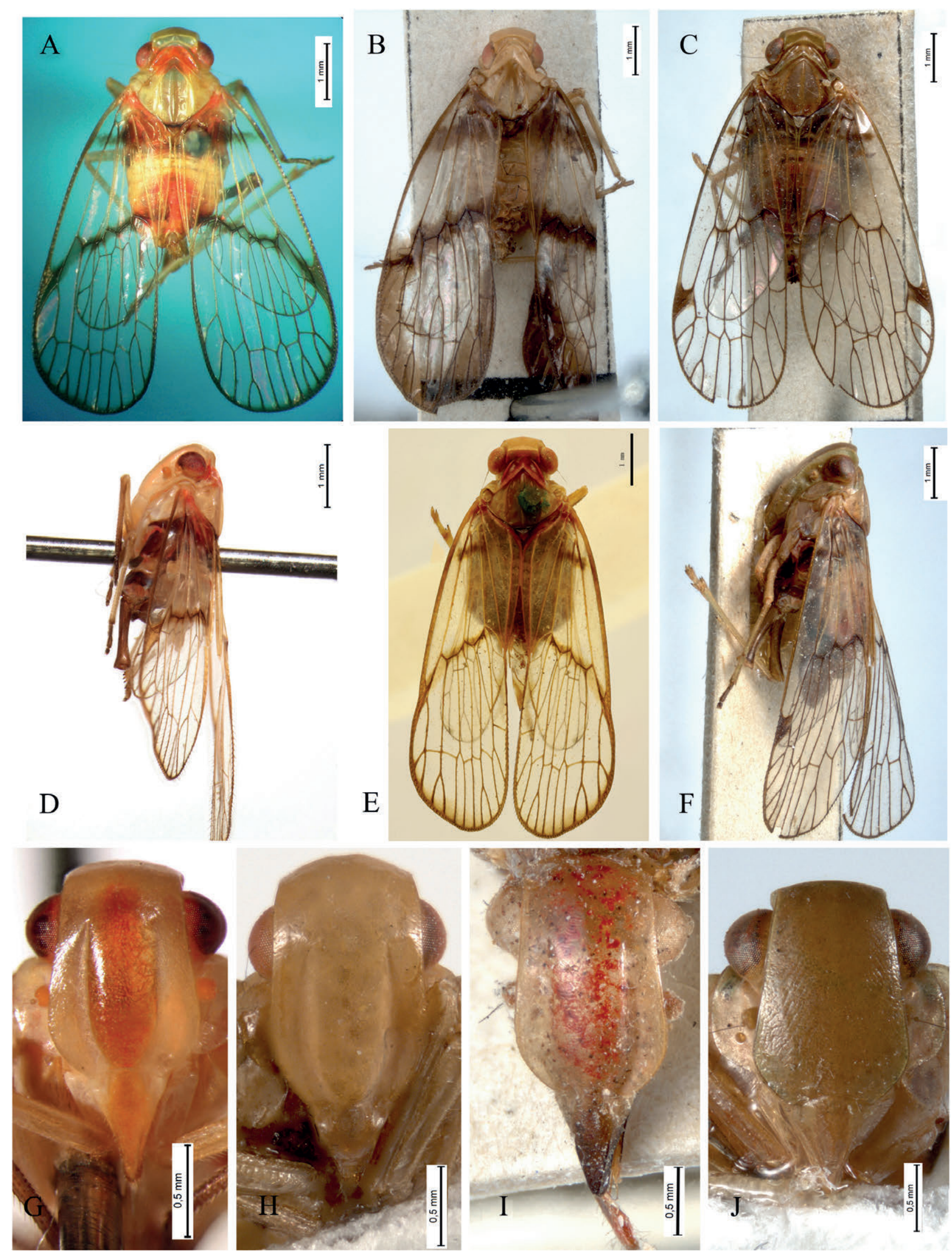

Fig. 2. Pseudoparicana species. A-C, E - dorsal habitus; D, F- lateral habitus; G-J - head, oblique ventral view. A, D, G - P. analoga Wang \& Malenovský sp. n. (holotype, đo, Papua New Guinea, CAS). B, H, I - P. sanguinifrons ( $ત$, Papua New Guinea, MMBC). C, F, J-P. tepida (paralectotype, +, Papua New Guinea, MMBC). E-P. curvifera (lectotype, ठ, Aru Islands, BMNH). 

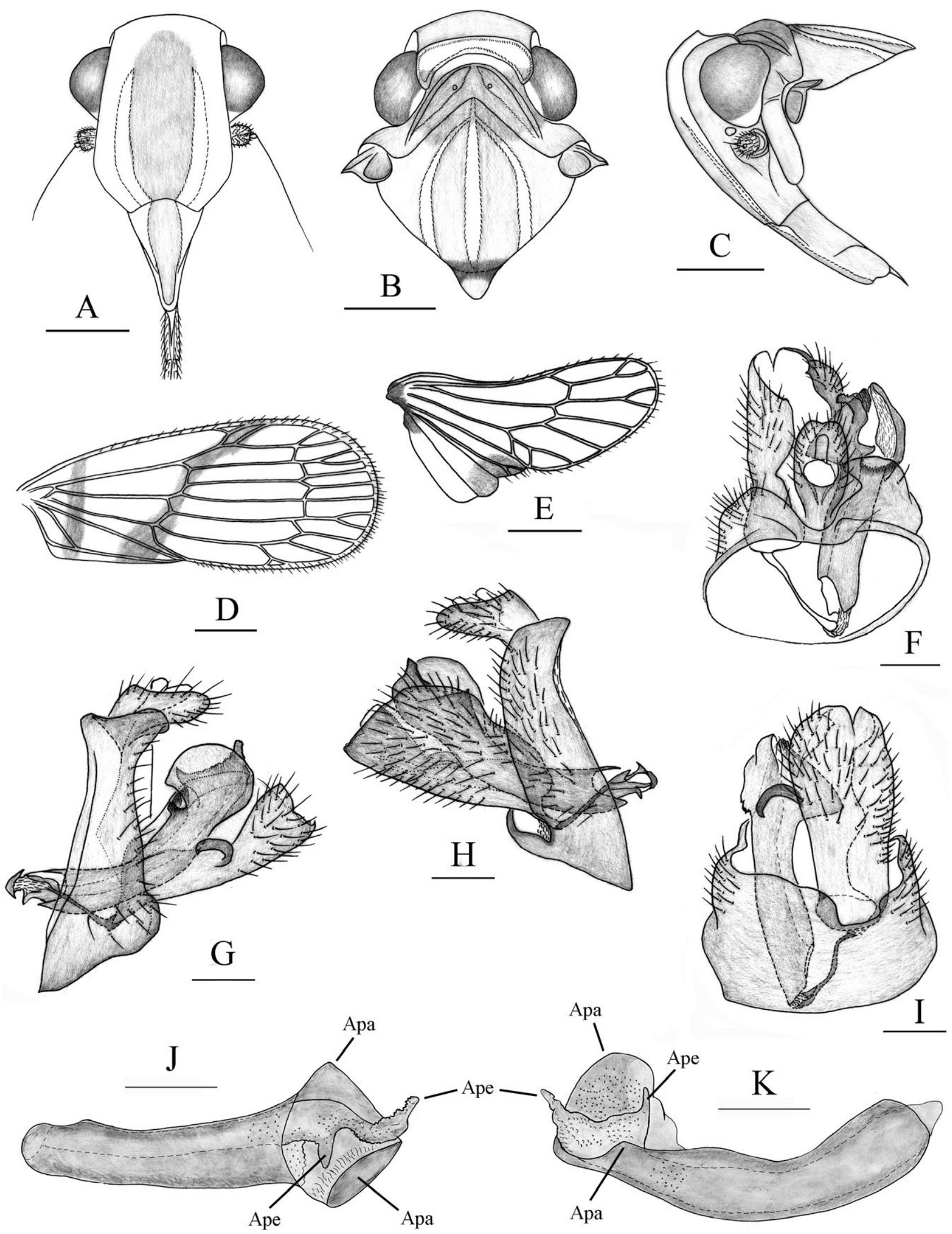

Fig. 3. Pseudoparicana analoga Wang \& Malenovský sp. n. (A-I, holotype, CAS; J-K, paratype, MMBC). A - head, oblique ventral view; $\mathrm{B}$ - head, pronotum and mesonotum, dorsal view; $\mathrm{C}$ - head, pronotum and mesonotum, lateral view; $\mathrm{D}$ - right fore wing; $\mathrm{E}$ - right hind wing; $\mathrm{F}$ - male genitalia, dorsal view; $\mathrm{G}$ - male genitalia, left lateral view; $\mathrm{H}$ - male genitalia, right lateral view; I - male genitalia, ventral view; $\mathrm{J}$ - aedeagus, dorsal view; $\mathrm{K}$ - aedeagus, right lateral view. Scale bars: $\mathrm{A}-\mathrm{C}=0.5 \mathrm{~mm}$; $\mathrm{D}, \mathrm{E}=$ $1 \mathrm{~mm} ; \mathrm{F}-\mathrm{K}=0.25 \mathrm{~mm}$. Abbreviations: Apa - apical process of aedeagus; Ape - apical process of endosoma. 

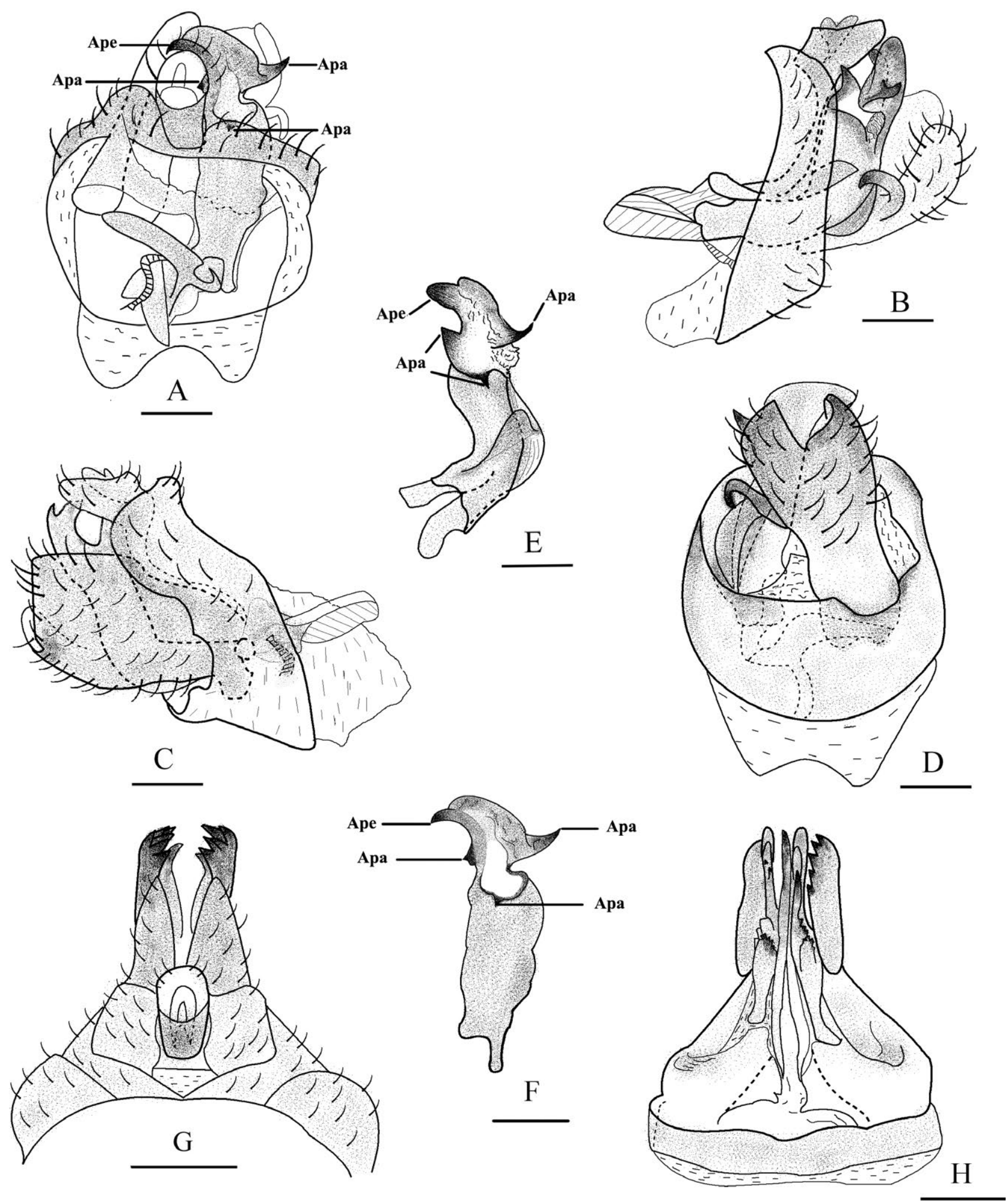

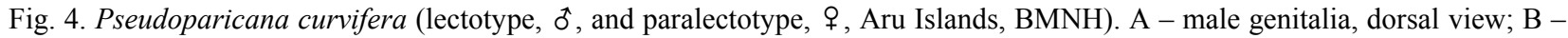
male genitalia, left lateral view; $\mathrm{C}$-male genitalia, right lateral view; D - male genitalia, ventral view; E - aedeagus, left dorsolateral view; $\mathrm{F}$ - aedeagus, dorsal view; $\mathrm{G}$ - female genitalia, dorsal view; $\mathrm{H}$ - female genitalia, ventral view. Scale bars: $\mathrm{A}-\mathrm{F}=0.25$ $\mathrm{mm} ; \mathrm{G}-\mathrm{H}=0.5 \mathrm{~mm}$. Abbreviations: Apa - apical process of aedeagus; Ape - apical process of endosoma.

single. Legs elongate; hind tibia with 3 distinct lateral spines; tibio-tarsal formula of hind leg 6-5-2.

Male genitalia. Asymmetrical, with inter-specific chiral dimorphism (Figs 3F-I, 4A-D, 5A-D, 7A-D).
Pygofer with left/right lateral margin dorsally produced into a lobe or tooth directed dorsocaudad. Anal tube (Xth segment) short, not surpassing apex of aedeagus; anal styles relatively small, not reaching the apico-ventral 

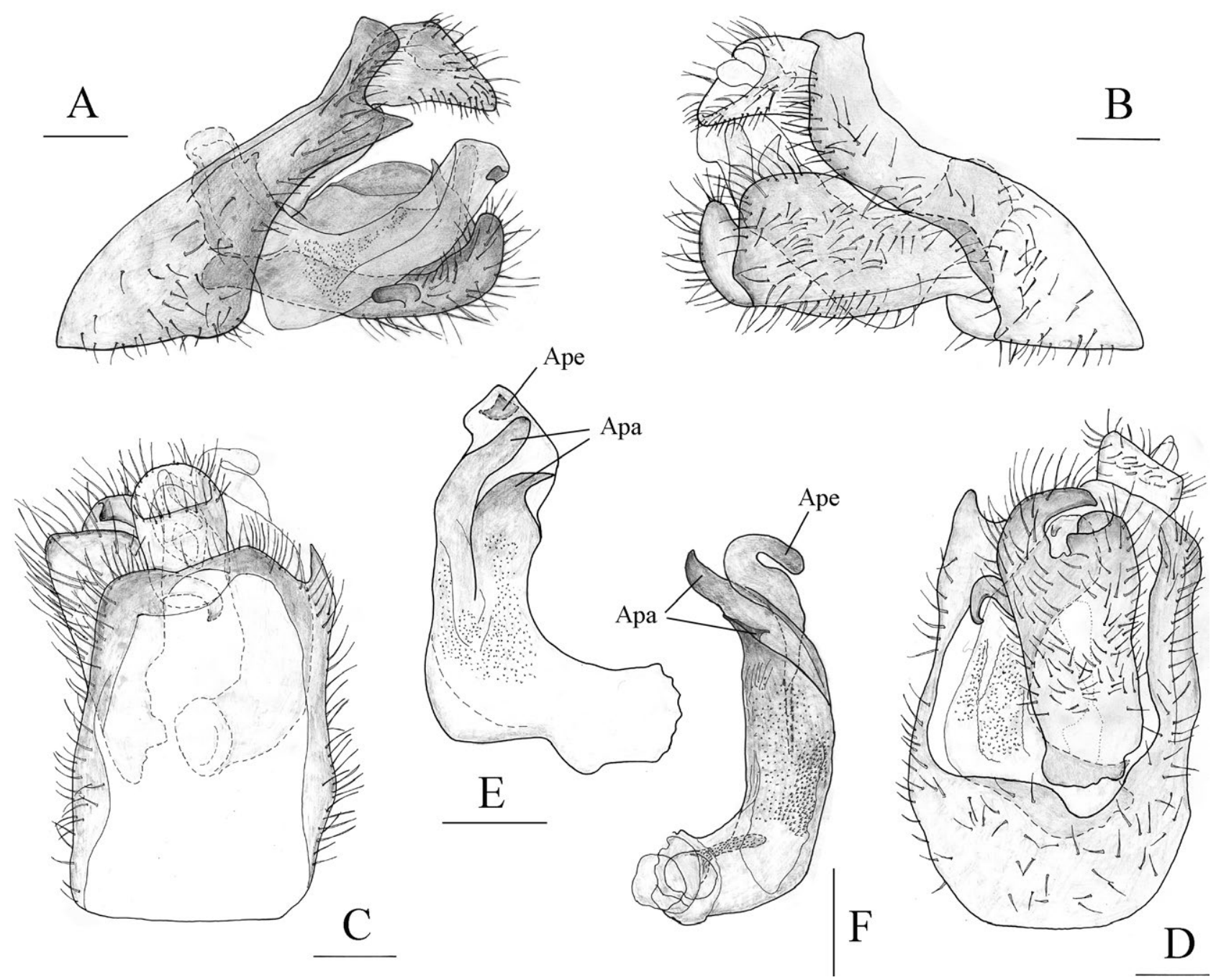

Fig. 5. Pseudoparicana sanguinifrons, male genitalia (Papua New Guinea, MMBC). A - left lateral view; B - right lateral view; C - dorsal view; D - ventral view; $\mathrm{E}$ - aedeagus, right lateral view; $\mathrm{F}$ - aedeagus, dorsal view. Scale bars: A-F $=0.25 \mathrm{~mm}$. Abbreviations: Apa - apical process of aedeagus; Ape - apical process of endosoma.

margin of anal tube in dorsal view. Gonostyli almost completely fused together into a curved plate, with a hook-like sclerotized process arising laterally from apical half on left/right side. Periandrium (Figs 3F-I, 4A-D) very short, ring-like, nearly indistinct, dorsally connected by a short membranous area bearing the tectiductus with ventrobasal margin of anal tube, fused by a membrane with pygofer laterally and ventrally, surrounds aedeagus basally. Aedeagus asymmetrical, tube-like, bearing species-specific shaped processes medially/distally (Figs 3J-K, 4E-F, 5E-F, 7E-F).

Female genitalia. Anal tube short, apical margin broadly rounded in dorsal view, anal styles short, not reaching the apico-ventral margin of anal tube (Figs 4G, 6B). Gonoplacs (third valvulae; Figs 4G-H, 6A-B, D-E) with 10-11 strongly sclerotized teeth arranged in two rows along apical margin. Gonapophyses VIII (first valvulae; Figs $4 \mathrm{H}, 6 \mathrm{~A}, \mathrm{D}-\mathrm{E}$ ) strongly sclerotized with $6-8$ blunt teeth on dorsal margin and three blunt teeth subapically on the ventral margin; base of gonapophyses VIII asymmetrical in ventral view (Figs 4H, 6D-E). Gonapo- physes IX (second valvulae; Fig. 6C) with apical ends confluent; gonospiculum shorter than medial length of triangular part $(0.8: 1)$. Gonocoxae VIII forming sclerotized plates slightly produced posteriorly in dorsal and ventral portions in lateral view. Genital opening (gonoporus) singular (monotrysian) occurring between gonapophyses VIII and IX. Sternite VII with posterior margin straight or shallowly sinuate, with a shallow obtusely angled notched in the middle in ventral view (Figs 4H, 6D) or broadly and shallowly V-shaped (Fig. 6E); in lateral view, straight ventrally. Posterior vagina wellsclerotized, bulbous (Figs 6A, D-E). Dorsally, a large bursa copulatrix opens directly into vagina and a small triangular common oviduct and spermatheca open apically into anterior vagina; bursa copulatrix superficially smooth, membranous, bladder-like or covered with numerous small, sharply triangular cuticular spines.

Distribution. Species of Pseudoparicana are currently known from the Aru Islands (administrative part of Indonesia) and New Guinea (Fig. 1). 


\section{Key to the species of Pseudoparicana}

1 Frons (Fig. 2J) regularly slightly convex, not swollen medially and lacking depressed grooves laterally. Fore wing membrane (Figs 2C, F) without dark brown markings extending along nodal line. Posterior margin of male pygofer ventrally with incision on left (sinistral) part; aedeagus situated on right side of gonostyli (Figs 7A-D). Aedeagus with a hook-like apical process on the endosoma, which extends well beyond the apex of the aedeagus (Figs 7E-F). . . . . . . . . . . . . . . P. tepida Melichar

- Frons (Figs 2G-I, 3A) swollen medially, depressed in longitudinal grooves and flattened laterally. Fore wing membrane (Figs 2A-B, D-E, 3D) with dark brown markings extending along nodal line. Posterior margin of male pygofer ventrally with incision on right (dextral) part (Figs 3I, 4D, 5D); aedeagus situated on left side of gonostyli (Figs 3F, 4A, 5C). Aedeagus with apical process of endosoma relatively small and differently shaped (Figs 3J-K, 4E-F, 5E-F). . . 2

2 Fore wing with wide pigmented bands (Fig. 2B). Aedeagus (Figs 5A, E-F) with apical part nearly parallel-sided, curved dorsad in left lateral view; right side with two large processes arising from aedeagus shaft medially; endosoma with a vermicular twisted process on left ventral side, directed obliquely cephalad. ............ P. sanguinifrons Muir

- Fore wing with relatively narrow pigmented bands (Figs 2A, E, 3D). Structure and shape of the aedeagus different. . . . . 3

3 Aedeagus with left apical part abruptly expanded into a subspherical form in lateral view (Figs $3 \mathrm{G}, \mathrm{K}$ ); in dorsal view, apex on right lateral side produced into a large triangular lobe (Figs 3F, J); endosoma with a relatively small sinuate apical process directed dorso-laterad and denticulate along its whole margin and a small sharp, spine like process situated sub-apically and directed mesio-dorsad (Figs 3J-K). Posterior margin of male pygofer dorsally produced into a blunt, tooth-like lobe directed dorso-caudad in left lateral view (Figs 3F-G), regularly convex in right lateral view (Fig. 3H). Gonostyli, in left lateral view, with truncate apex (Fig. 3G).......... . analoga Wang \& Malenovský sp. n.

- Aedeagus (Figs 4A-F) with apical part slightly expanded, curved dorsad in left lateral view; in dorsal view, sub-apical part on right and dorsal side with two spine-like processes, directed laterad and dorsad, respectively (Figs 4A, E-F); apex on left dorsal side with one large, spine-like twisted process directed ventro-laterad; endosoma with a relatively large spine-like process with a smooth margin (Figs 4A, E-F). Posterior margin of male pygofer nearly straight in left lateral view (Fig. 4B), produced into a broadly obtuse lobe dorsally in right lateral view (Fig. 4C). Gonostyli, in left lateral view, with obtusely rounded apex (Fig. 4B).....

\section{Pseudoparicana analoga Wang \& Malenovský sp. n.}

(Figs 2A, D, G, 3A-K)

\section{Description}

Size. Male. Total length (from apex of vertex to tip of fore wings): 6.8-7.4 $\mathrm{mm}$ (holotype 6.8); body length (from apex of vertex to tip of anal tube): $4.0-5.1 \mathrm{~mm}$ (holotype 4.1); fore wing length: 5.7-6.3 mm (holotype 5.7).

Coloration. General colour of body pale yellow. Clypeus and median swollen portion of frons orange to red. Posterior lateral corners of vertex, eyes, disc of pronotum, anterior portion of mesonotum and dorsum of abdomen all suffused with red. Mesonotum with trans- verse suture black. Mesopleura with large orange stripes, metapleura reddish black. Fore wings hyaline, marked with two narrow dark brown transverse bands sub-basally and on nodal line; apical margin narrowly bordered dark brown in posterior third; scutellar border red. Hind wings hyaline, veins dark brown, anal area infuscated apically. Legs yellow, hind coxae, trochanters, femora, fore tibia, and tarsi all infuscated dark brown; apices of all spines black. Freshly emerged specimens uniformly pale yellow.

Head and thorax. Frons (Figs 2G, 3A, C) smooth, shiny, sub-rectangular, its length along midline greater than maximum width $(1.32: 1)$, with a broadly swollen median part, delimited laterally on each side by grooves converging down to frontoclypeal suture, flattened laterally; in lateral view, disc shallowly depressed from basal $1 / 3$ to frontoclypeal suture. Fore wings (Figs 2A, D, 3D) 2.4 times as long as maximally wide; gradually broaden towards apical margin, widest near apex; apical margin broadly rounded, almost truncate.

Male genitalia. Pygofer asymmetrical, narrow and high in lateral view; in left view (Fig. 3G), wider ventrally than dorsally, with posterior margin dorsally produced into a blunt, tooth-like lobe directed dorso-caudad (Figs $3 \mathrm{~F}-\mathrm{G}$ ); in right lateral view (Fig. $3 \mathrm{H}$ ), posterior margin regularly convex; in ventral view (Fig. 3I), posterior margin of pygofer with right (dextral) part with a U-shaped excavation to accommodate gonostyli. Anal tube (Figs 3F-H) short; in lateral view, expanded and decurved in distal half from the axis of the basal half; in dorsal view, basal part distinctly narrowed, expanded toward apex, apical margin truncate. Gonostyli (Figs $3 \mathrm{~F}-\mathrm{I})$ fused together, distinctly curved along medial axis and forming a sub-cylindrical structure, joined by membrane to pygofer at base; in left lateral view (Fig. 3G), spade-like, with truncate apex and a relatively long curved, hook-like and strongly sclerotized process arising on apical half on left side of gonostyli and directed dorsocephalad (Fig. 3I); in right lateral view (Fig. 3H), gonostyli broad, without process on right side laterally. Aedeagus situated left of gonostyli (Figs 3F-I), asymmetrical, tube-like; in lateral view (Figs $3 \mathrm{G}, \mathrm{K}$ ), left distal part abruptly expanded into a sub-spherical lobe oriented dorsad; in dorsal view, apex on right lateral side produced into a broad triangular process directed laterad (Figs 3F, I-J); endosoma with two narrow apical processes: one spine-like, situated proximally and directed dorso-mesiad and another sinuate, denticulate along its margin, situated distally and directed dorso-laterad (Figs 3J-K); phallotreme split-like, running along the apex of aedeagus, forming a distinct longitudinal furrow.

\section{Female genitalia. Unknown.}

Type material. Holotype $\widehat{\delta}$, Papua New Guinea: Madang Province, $2 \mathrm{~km} \mathrm{~W}$ of North Coast Road at Matukar, $40 \mathrm{~m}$, 6.iii.1989, D.H. Kavanaugh, G.E. Ball \& N.D. Penny leg. (CAS). Paratypes: $3 \hat{0}$, Papua New Guinea: Madang Province, Baitabang village, Kau Wildlife Area, $5^{\circ} 08^{\prime} \mathrm{S}, 145^{\circ} 45^{\prime} \mathrm{E}, 50 \mathrm{~m}$, 21.ix.-22.xii.1999, primary forest, Malaise trap, L. Č́žžek leg.; 10, same data but 2.ii.-19.ii.2000 (MMBC).

Etymology. From the adjective analogus, Latinized form of

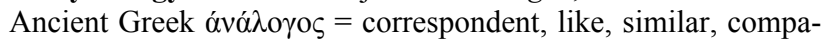




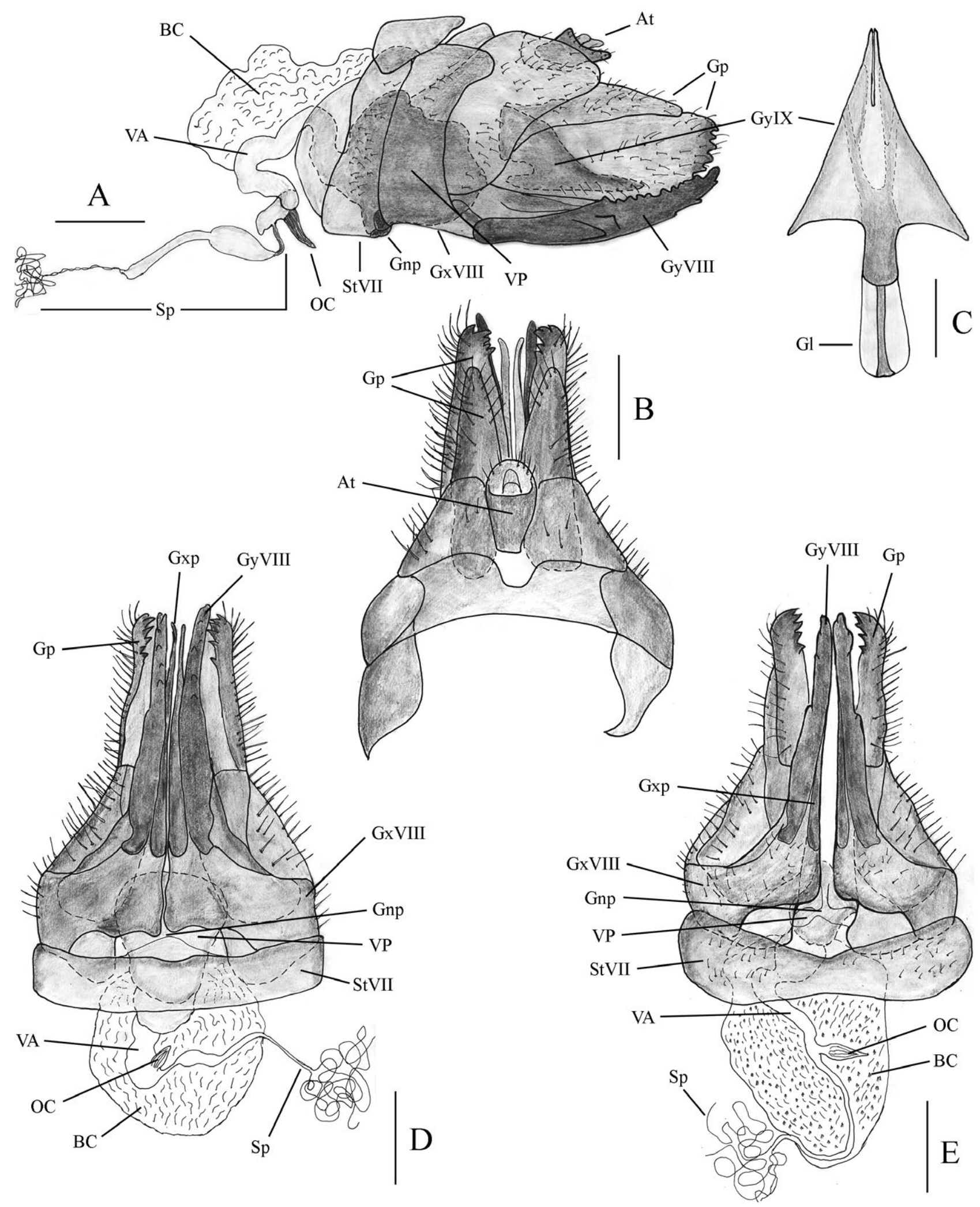

Fig. 6. A-D - Pseudoparicana sanguinifrons, female genitalia (Papua New Guinea, MMBC). A - left lateral view; B - dorsal view; C - gonapophyses IX and gonospiculum; D - ventral view. E - P. tepida, female genitalia, ventral view (paralectotype, Papua New Guinea, MMBC). Scale bars: A, B, D, E $=0.5 \mathrm{~mm}, \mathrm{C}=0.25 \mathrm{~mm}$. Abbreviations: At - anal tube; BC - bursa copulatrix; GI gonospiculum; Gnp - gonoporus; Gp - gonoplac; GxVIII - gonocoxae VIII; Gxp - endogonocoxal process; GyVIII - gonapophyses VIII; OC - common oviduct; Sp - spermatheca; StVII - sternite VII; VA - anterior vagina; VP - posterior vagina.

rable. The new species so named because in general appearance it is similar to $P$. curvifera (Distant, 1907).

Distribution. North-eastern New Guinea (Fig. 1).
Remarks. $P$. analoga Wang \& Malenovský sp. n. is similar to $P$. curvifera externally but can be distinguished 

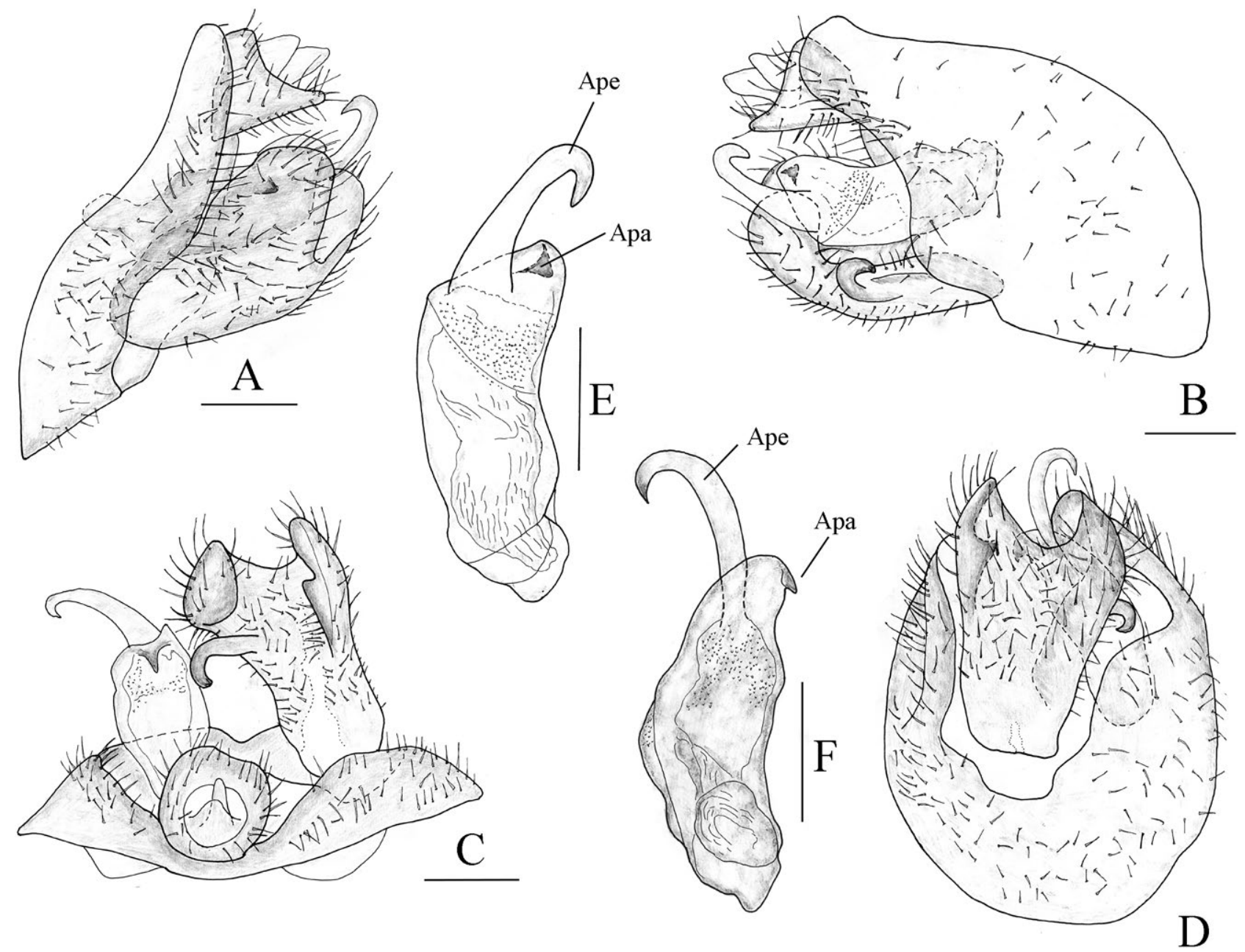

Fig. 7. Pseudoparicana tepida, male genitalia (lectotype, Papua New Guinea, MMBC). A - left lateral view; B - right lateral view; $\mathrm{C}$ - dorsal view; $\mathrm{D}$ - ventral view; $\mathrm{E}$ - aedeagus, right lateral view; $\mathrm{F}$ - aedeagus, dorsal view. Scale bars: $\mathrm{A}-\mathrm{F}=0.25 \mathrm{~mm}$. Abbreviations: Apa - apical process of aedeagus; Ape - apical process of endosoma.

from the latter by the shape of the male pygofer, gonostyli and aedeagus as indicated in the corresponding key couplet above.

\section{Pseudoparicana curvifera (Distant, 1907)}

(Figs 2E, 4A-H)

Paricana curvifera Distant, 1907: 288. Lectotype ô, Aru Islands [deposited in BMNH, here designated, examined].

Pseudoparicana curvifera, Melichar, 1914: 112; Metcalf, 1954: 134; Wilson \& Malenovský, 2007: 147.

\section{Description}

Size. Male. Total length (from apex of vertex to tip of fore wings): $7.5 \mathrm{~mm}$; body length (from apex of vertex to tip of anal tube): $5.0 \mathrm{~mm}$; fore wing length: $6.2 \mathrm{~mm}$. Female. Total length: $8.1 \mathrm{~mm}$; fore wing length: $6.8 \mathrm{~mm}$.

Coloration, head and thorax as in $P$. analoga Wang \& Malenovský sp. n.

Male genitalia. Pygofer asymmetrical, narrow and high in lateral view; in left view (Fig. 4B), wider ventrally than dorsally, posterior margin nearly straight, truncate; in right lateral view (Fig. 4C), with posterior margin dorsally produced into a broadly obtuse lobe directed dorsocaudad; in ventral view (Fig. 4D), posterior margin of pygofer with U-shaped depression on right (dextral) part to accommodate gonostyli. Anal tube (Figs 4A-C) short; in lateral view, slightly expanded and decurved in distal half from the axis of the basal half; in dorsal view, basal part narrowed, expanded toward apex, apical margin rounded. Gonostyli (Figs 4B-D) fused together, distinctly curved along medial axis and forming a sub-cylindrical structure, joined by a membrane to base of pygofer; in left lateral view (Fig. 4B), narrow at base, with obtuse apex and a relatively long curved, hook-like and strongly sclerotized process arising on apical half on left side of gonostyli and directed dorso-cephalad; in right lateral view (Fig. 4C), gonostyli broad, without process on right side laterally, apex truncate. Aedeagus situated left of gonostyli (Figs 4A-D), asymmetrical, tube-like; in left lateral view (Figs 4B, E), distal part slightly expanded; in dorsal view (Figs 4A, F), sub-apical part on right side with two spine-like processes, directed laterad and dorsad, respectively (Figs 4A, E-F); apex on left dorsal side with one large twisted process, directed ventrolaterad; endosoma with a large spine-like process; phallotreme (Figs 4A, E-F) trumpet-like, running along the apex of aedeagus, forming a distinct, wide opening. 
Female genitalia. Gonoplacs with 11 strongly sclerotized teeth along apical margin arranged in two rows (Figs 4G-H). Gonapophyses VIII strongly sclerotized with 7 blunt teeth on dorsal margin; base of gonapophyses VIII asymmetrical in ventral view: left part produced into two small, tooth-like lobes, right part expanding into one relatively long lobe (Fig. 4H). Sternite VII with posterior margin shallowly sinuate, shallowly notched in obtuse angle at middle in ventral view (Fig. 4H).

Type material examined. Lectotype $\hat{\sigma}$, Indonesia: Maluku province, Aru Islands, "67 66" [1866-1867], A.R. Wallace leg. (here designated, BMNH). Paralectotypes $1 \hat{\delta}, 1$ 옹 same data as lectotype (BMNH).

Distribution. Aru Islands (Fig. 1).

Remarks. $P$. curvifera is similar to $P$. analoga Wang \& Malenovský sp. n. externally, but can be distinguished from the latter by the shape of the male pygofer, gonostyli and aedeagus (see the key above). The female of $P$. curvifera differs from $P$. sanguinifrons and $P$. tepida in the shape of the base of the gonapophyses VIII.

A comparison with the corresponding type material revealed that one male and one female specimen from "Fiume Purari" deposited in L. Melichar collection (MMBC) and cited as Pseudoparicana curvifera by Melichar (1914) and Wilson \& Malenovský (2007) were misidentified and belong to $P$. sanguinifrons.

\section{Pseudoparicana sanguinifrons Muir, 1931}

(Figs 2B, H-I, 5A-F, 6A-D)

Pseudoparicana sanguinifrons Muir, 1931: 75. Syntypes 10, $2 \uparrow$, New Guinea, Fly River [deposited in BMNH, 19 examined].

Pseudoparicana sanguinifrons, Metcalf, 1954: 134; Fennah, 1982: 636, Fig. 23

\section{Description}

Size. Male. Total length (from apex of vertex to apex of fore wings): $8.1 \mathrm{~mm}$; fore wing length: $7.1 \mathrm{~mm}$. Female. Total length: $8.6-8.9 \mathrm{~mm}$; fore wing length: $7.2-7.5 \mathrm{~mm}$.

Coloration. General colour of body straw yellow. Frons (Figs 2H-I) uniformly yellow or the swollen middle portion reddish. Clypeus dark brown to black. Posterior tip of mesonotum narrowly and mesoscutellum entirely dark brown to black. Fore wings (Fig. 2B) hyaline with two well-delimited and relatively broad transverse dark brown bands, one situated sub-basally, the other along nodal line; apical margin of fore wing widely bordered dark brown in posterior third (dark coloration of membrane extending from node round wing apex nearly to clavus); scutellar border red. Legs yellowish or light brownish, coxae dark brown to black, femora ventrally, fore tibia entirely, mid and hind tibiae basally and tarsi all infuscated dark brown; apices of all spines on legs black. Abdomen light ochreous to reddish brown basally, darker brown in the mid-dorsal portion, two apical sternites dark brown to black.

Head and thorax. Frons (Figs 2H-I) smooth, shiny, sub-rectangular, its length along midline greater than maximum width $(1.5: 1)$, with broadly swollen median part, laterally delimited on each side by grooves converging down to frontoclypeal suture, flattened laterally; in lateral view, disc shallowly depressed from basal $1 / 2$ to frontoclypeal suture. Fore wings (Fig. 2B) 2.54-2.67 times as long as maximum width, gradually broadened towards apical margin, widest near apex; apical margin broadly rounded, almost truncate.

Male genitalia. Pygofer asymmetrical; in left lateral view (Fig. 5A), narrow and high, wider ventrally than dorsally, with posterior margin produced into a large, sharply triangular tooth on dorsal third, directed dorsocaudad; in right lateral view (Fig. 5B), pygofer narrow, with posterior margin regularly convex in dorsal part; in ventral view (Fig. 5D), posterior margin of pygofer with right (dextral) part widely excavated to accommodate gonostyli. Anal tube (Xth segment; Figs 5A-C) short, expanded and slightly decurved in distal half from the axis of the basal half in lateral view; apical margin irregularly rounded in dorsal view. Gonostyli (Figs 5A-B, D) fused together, distinctly curved along medial axis and forming a sub-cylindrical structure, with a rounded, strongly curved apex in left lateral (Fig. 5A) and ventral view (Fig. 5D), and a relatively long curved, hook-like and strongly sclerotized process arising on apical half on left side of gonostyli and directed dorso-cephalad (Figs 5A, C-D); in right lateral view (Fig. 5B), gonostyli broadly truncate at apex, without process on lateral side. Aedeagus (Figs 5A, E-F) situated left of gonostyli, asymmetrical, tubular-like; in left lateral view, with apical part nearly parallel-sided, slightly curved dorsad; right lateral side of aedeagus with two large processes arising from aedeagus shaft medially: in right lateral view, one is long and runs along ventral margin of aedagus, blunt at apex, the other small, tooth-like, with sharp apex, oriented dorsad; endosoma with a vermicular twisted apical process on left side, directed obliquely cephalad (Fig. 5F). Phallotreme split-like, forming a longitudinal furrow.

Female genitalia. Gonoplacs (third valvulae; Figs 6A-B) with 11 strongly sclerotized teeth arranged in two rows along apical margin. Gonapophyses VIII (first valvulae; Figs 6A, D) strongly sclerotized with 6 blunt teeth on dorsal and three on ventral margin; base of gonapophyses VIII asymmetrically sinuate in ventral view: left part produced into one stout lobe, right part expanding into one relatively small lobe; apices of both lobes narrowly rounded (Fig. 6D). Sternite VII with posterior margin nearly straight, shallowly notched medially (Fig. 6D). Posterior vagina large, well-sclerotized, pear-shaped in ventral view (Fig. 6D). Bursa copulatrix membranous, bladder-like, with surface smooth, lacking distinct microsculpture.

Type material examined. Syntype $q$, Papua New Guinea: Western Province, Fly River, Geographical Society's Expedition, K55378 (BMNH).

Other material examined. 10 , 19 , Papua New Guinea, Gulf province, "Fiume Purari" [Purari River], January 1894, L. Loria leg. (L. Melichar collection, MMBC).

Distribution. South-eastern New Guinea (Fig. 1). 
Remarks. $P$. sanguinifrons can be differentiated from the related species by its slightly larger size, extended dark markings on the fore wings, presence of a sharp triangular tooth on the left posterior margin of male pygofer and the structure of the gonostyli and aedeagus. The female differs from $P$. curvifera and $P$. tepida also in the shape of the base of gonapophyses VIII.

The male and female specimens from "Fiume Purari" were misidentified and cited under $P$. curvifera by Melichar (1914) and Wilson \& Malenovský (2007).

\section{Pseudoparicana tepida Melichar, 1914}

(Figs 2C, F, J, 6E, 7A-F)

Pseudoparicana tepida Melichar, 1914: 113. Lectotype đิ, New Guinea, Dilo [deposited in MMBC, here designated, examined].

Pseudoparicana tepida, Metcalf, 1954: 134; Wilson \& Malenovský, 2007: 146.

\section{Description}

Size. Male. Total length (from apex of vertex to apex of fore wings): $7.3 \mathrm{~mm}$; fore wing length: $6.1 \mathrm{~mm}$. Female. Total length: 7.7-8.2 mm; body length (from apex of vertex to apex of abdomen): $5.2-6.2 \mathrm{~mm}$; fore wing length: $6.7-6.9 \mathrm{~mm}$.

Coloration. General colour of body (Figs 2C, F) brownish yellow. Frons, clypeus (Fig. 2J), vertex, pronotum and major portions of mesonotum and scutellum uniformly dirty yellow to brownish yellow; posterior fifth of mesonotum light brown; mesoscutellum basally narrowly dark brown. Pleural sclerites of thorax marked with dark brown. Fore wings hyaline, marked with a not clearly delimited narrow transverse dark brown band subbasally; nodal line and node dark brown but dark coloration restricted to veins, hardly extending into membrane in adjacent cells; apical margin of forewing clear, lacking dark markings; a small basal portion of scutellar border red. Legs yellowish or light brownish, coxae dark brown to black, hind femora and tarsi infuscated dark brown; apices of all spines on legs black. Abdomen light ochreous, reddish brown in the mid-dorsal portion, two apical sternites dark brown to black.

Head and thorax. Frons (Fig. 2J) with distinct microsculpture, moderately shiny, sub-rectangular, its length along midline greater than maximum width $(1.35$ : 1), regularly slightly convex, lacking a swollen median part and depressed grooves laterally; in lateral view, disc shallowly depressed from basal $1 / 3$ to frontoclypeal suture. Fore wings (Figs 2C, F) 2.44-2.54 times as long as maximally wide; gradually broadened towards apical margin, widest sub-apically; apical margin broadly but evenly rounded.

Male genitalia. Pygofer asymmetrical; in left lateral view (Fig. 7A), narrow and high, slightly wider ventrally than dorsally, posterior margin regularly convex in dorsal half; in right lateral view (Fig. 7B), pygofer broad, concave medially, produced into a broadly rounded lobe dorsally; in ventral view (Fig. 7D), posterior margin of pygofer with left (sinistral) part widely excavated to accommodate gonostyli. Anal tube very short, in lateral view (Figs 7A-B) nearly triangular; in dorsal view (Fig. 7C), round, with apical margin slightly concave. Gonostyli fused together, distinctly curved along medial axis and forming a sub-cylindrical structure; in left lateral view (Fig. 7A), with a broadly rounded apex; in dorsal view (Fig. 7C), with a sclerotized tooth on inner side of left dorsal margin medially and a relatively long curved, hook-like and strongly sclerotized process arising on apical half on right side of gonostyli and directed dorsocephalad; in right lateral view (Fig. 7B), gonostyli distinctly curved and apically rounded. Aedeagus situated right of gonostyli (Figs 7A-D), asymmetrical, tubularlike, shaft bearing a small sclerotized tooth-like apical process dorsally (Figs 7C, E-F); in right lateral view (Fig. 7E), apex of aedeagus broadly truncate; endosoma with a large hook-like apical process largely surpassing aedeagus apex (Figs 7E-F). Phallotreme running along the apex of aedeagus, forming a distinct, wide opening.

Female genitalia. Gonoplacs with 10 strongly sclerotized teeth arranged in two rows along apical margin. Gonapophyses VIII strongly sclerotized with 6-8 blunt teeth on dorsal and three on ventral margin; base of gonapophyses VIII asymmetrical in ventral view: left part with broadly rounded apex, right part distinctly sinuate subapically (Fig. 6E). Sternite VII with posterior margin shallowly and broadly $\mathrm{V}$-shaped, indistinctly notched at middle in ventral view (Fig. 6E). Posterior vagina relatively small, irregularly heart-shaped in ventral view (Fig. $6 \mathrm{E})$. Bursa copulatrix membranous, bladder-like with surface covered in numerous small sclerotized cuticular spines, sharply triangular or bifid at apex.

Type material examined. Lectotype $\hat{\delta}$, Papua New Guinea: Central Province, Dilo [a small village along the Kemp Welch River, approximately $\left.9^{\circ} 55^{\prime} \mathrm{S}, 147^{\circ} 45^{\prime} \mathrm{E}\right]$, vi.-vii.1890, L. Loria leg. (here designated, L. Melichar collection, MMBC, type registration number 4342). Paralectotypes: $2 \%$, same data as lectotype (L. Melichar collection, MMBC, type registration numbers 4340 and 4341).

Distribution. South-eastern New Guinea (Fig. 1).

Remarks. P. tepida differs from all other Pseudoparicana species in its regularly convex frons lacking a median swelling and lateral grooves, the absence of a distinct dark brown band extending into the membrane along the nodal line on the fore wings, a more evenly rounded fore wing apex lacking dark brown pigmentation, and the structure of the male genitalia, including its chirality, the shape of the pygofer, the presence of a sclerotized tooth on the left latero-dorsal margin of the gonostyli, and the form of the aedeagus and its processes. The female differs from $P$. curvifera and $P$. sanguinifrons in the shapes of the posterior margin of sternite VII and the base of gonapophyses VIII and from $P$. curvifera also in the smaller posterior vagina and microsculpture on the bursa copulatrix.

Melichar's drawing of a dorsal view of the head of $P$. tepida (Melichar, 1914: 113, Fig. 27) is wrong in showing a median carina on the vertex. In fact, the three syntype specimens examined do not have such a carina. 
One female paralectotype of $P$. tepida is parasitized by a female of Strepsiptera, tentatively identified as Halictophagus sp. Halictophagus Curtis, 1831 is a large cosmopolitan genus comprising 97 species associated with various families of Auchenorrhyncha (Kathirithamby \& Moya-Raygoza, 2000; Kathirithamby, 2012). Two species of Halictophagus are recorded from New Guinea: $H$. ancylophallus Kifune \& Hirashima, 1989 and H. eurycephalus Kifune \& Hirashima, 1989 (Kifune \& Hirashima, 1989; Kathirithamby, 2012). More material, particularly males, is needed for a precise identification of the parasite.

\section{Pseudoparicana sp. indet.}

Material examined. 19 , Indonesia: West Papua province, Ramoi, 1872, L.M. D'Albertis leg. (L. Melichar collection, MMBC). 3 (one lacking abdomen), Indonesia: Papua province, Sentani lake [east of lake, approximately $2^{\circ} 36^{\prime} \mathrm{S}$, $140^{\circ} 37^{\prime}$ E, J. Kolibáč, pers. comm.], 300 m, iii.1992, J. Kolibáč leg. (ZSM).

Remarks. The above cited females collected in northwestern and northern New Guinea (Fig. 1) are similar to $P$. analoga Wang \& Malenovský, sp. n. and P. curvifera in general habitus, particularly the fore wing pattern with two well-distinct, narrow, transverse brown bands. The base of gonapophyses VIII is broadly irregularly rounded and lacks distinct tooth-like lobes as in P. curvifera. The identification of these specimens is uncertain - they may belong to $P$. analoga Wang \& Malenovský, sp. n. (for which no female has been collected at the type locality) or to one or two additional, undescribed species. More material, particularly of the males, is needed for identification.

\section{DISCUSSION}

\section{Systematic position and diagnosis of the genus}

In the absence of a phylogenetic analysis of Tropiduchidae, which would test homologies of morphological characters, the systematic position of Pseudoparicana within the family remains enigmatic. Melichar (1914) included it in the tribe Paricanini, defined by him mainly by the elongate forewing with the nodal line situated basad of the middle, the apical part longer than the corium and the presence of short erect setae on veins. Fennah (1982) transferred Pseudoparicana to the Tropiduchini, apparently based e.g. on the asymmetrical, fused gonostyli shared with some twenty other genera. In general habitus, Pseudoparicana is similar to Paricana Walker, 1857 (Paricanini) and Dichoneura Lethierry, 1890 (transferred from Delphacidae to Tropiduchidae: Cyphoceratopini by Fennah, 1982).

Pseudoparicana represents a distinct taxon within Tropiduchidae which can be diagnosed e.g. by forewing venation. The vein $\mathrm{CuA}$ forks at the nodal line that does not include the apex of the clavus. The free basal part of $\mathrm{CuA}_{2}$ is short, curved before merging into the postclaval margin of the tegmen. This fusion results in cell $\mathrm{C} 5$ being delimited by icu, $\mathrm{CuA}_{1}$ and the postclaval margin. This might represent an apomorphy for the genus, while a similar condition is approached, but probably independently due to tegmina reduction, in some brachypterous tropiduchid genera such as Durium Stål, 1861 and Neommatissus Muir, 1913. C5 is also apically open and closed by the postclaval margin in Trypetimorpha Costa, 1862 and Ommatissus Fieber, 1875. In Paricana and Dichoneura the transverse veinlet uniting $\mathrm{CuA}_{2}$ and the postclaval margin is present as in most other tropiduchids, and the branch $\mathrm{CuA}_{2}$ does not fuse with the postclaval margin, reaching the margin as a normally developed terminal.

\section{Chirality of male genitalia}

Asymmetry of genitalia might have important implications for understanding genital evolution and sexual selection (Eberhard, 2010). It is common in several different groups of insects and a consequence of convergent evolution from a symmetric situation (Huber et al., 2007; Huber, 2010; Schilthiuzen, 2007). In planthoppers, it has also been mentioned in Delphacidae, which exhibit almost exclusively an asymmetric morphology (Guglielmino \& Bückle, 2010). In Tropiduchidae, asymmetry is widely found in the male aedeagus, periandrium, pygofer and gonostylus, and in the female gonocoxae VIII and sternite VIII (Wang et al., 2009). Asymmetry of genital structures (genital styles) was mentioned as a feature of the tribe Tropiduchini by Fennah (1982). In Pseudoparicana, asymmetry concerns the male aedeagus, pygofer and gonostyli (Figs 3F-K, 4A-F, 5A-F, 7A-F), and the female gonocoxae VIII (Figs 4G, 6D-E).

Interestingly, in this genus, left- or right-handed asymmetry (chirality) of the male genitalia occurs: the male genitalia of $P$. analoga, $P$. curvifera and $P$. sanguinifrons are "left-handed" while that of $P$. tepida are "righthanded". Within the Tropiduchidae, the chirality of the male genitalia seems also to be a diagnostic character at the species level in some other genera, e.g. Daradax Walker, 1857, Tropiduchus Stål, 1854, Vanua Kirkaldy, 1906 and Varma Distant, 1906. However, in some Delphacidae, chiral dimorphism (right or left anti-symmetry of aedeagus) can occur within a single species (Guglielmino \& Bückle, 2010).

ACKNOWLEDGEMENTS. We wish to express our sincere thanks to J. Szwedo (Polish Academy of Sciences, Warsaw, Poland), P. Štys (Charles University, Prague, Czech Republic) and an anonymous reviewer for valuable suggestions and critical comments on the manuscript. Our thanks are also extended to L. Čížek (Institute of Entomology, Czech Academy of Sciences, České Budějovice, Czech Republic), P. Lauterer (Brno, Czech Republic), D. Ouvrard and M. Webb (both of the Natural History Museum, London, UK), N. Penny (California Academy of Sciences, San Francisco, California, USA) and B. Stock (the Bavarian State Collection of Zoology, Munich, Germany) for a gift or loans of the material examined. Our research was supported by the National Natural Science Foundation of China (grant nos. 31270043 and 30900145, awarded to RRW, 30970400 and 31172128, awarded to APL), the Key Laboratory of the Zoological Systematics and Evolution of the Chinese Academy of Sciences (grant no. O529YX5105, awarded to APL), the National Science Fund for Fostering Talents in Basic Research (Special subjects in animal taxonomy, NSFCJ0630964/J0109, awarded to APL) and the Ministry of Culture 
of the Czech Republic (grant no. MK000094862, awarded to the Moravian Museum, Brno).

\section{REFERENCES}

Bourgoln T. \& Huang J. 1990: Morphologie comparée des genitalia mâles des Trypetimorphini et remarques phylogénétiques (Hemiptera: Fulgoromorpha: Tropiduchidae). - Ann. Soc. Entomol. Fr. 26: 555-564.

BourgoIn T. 1993: Female genitalia in Hemiptera Fulgoromorpha, morphological and phylogenetic data. - Ann. Soc. Entomol. Fr. 93: 225-244.

Bourgoln T. 1997: The Meenoplidae (Hemiptera, Fulgoromorpha) of New Caledonia, with a revision of the genus Eponisia Matsumura, 1914, and new morphological data on forewing venation and wax plate areas. - Mém. Mus. Natl. Hist. Nat. Fr. (N.S.) (A, Zool.) 171: 197-249.

Bourgoln T. 2012: FLOW (Fulgoromorpha Lists on The Web): A World Knowledge Base Dedicated to Fulgoromorpha. Version 8, updated 26 August 2012. http://flow.snv.jussieu.fr/

Distant W.L. 1907: Rhynchotal notes xli. - Ann. Mag. Nat. Hist. Lond. (Ser. 7) 19: 277-295.

EBERHARD W.G. 2010: Evolution of genitalia: theories, evidence, and new directions. - Genetica 138: 5-18.

FenNah R.G. 1982: A tribal classification of the Tropiduchidae (Homoptera: Fulgoroidea), with the description of a new species on tea in Malaysia. - Bull. Entomol. Res. 72: 631-643.

Guglielmino A. \& BücKle C. 2010: Revision of Chlorionidea Löw (Hemiptera: Delphacidae) with the description of two new species from Italy, and comments on anti-symmetry in male genitalia of Delphacidae. - J. Nat. Hist. 44: $2737-2759$.

Huber B.A. 2010: Mating positions and the evolution of asymmetric insect genitalia. - Genetica 138: 19-25.
Huber B.A., Sinclair B. \& Schmitt M. 2007: The evolution of asymmetric genitalia in spiders and insects. - Biol. Rev. Camb. Philos. Soc. 82: 647-698.

ICZN (International Commission on Zoological Nomenclature) 1999: International Code of Zoological Nomenclature. Fourth Edition. The International Trust for Zoological Nomenclature c/o the Natural History Museum, London, 271 pp.

KathiRithamby J. 2012: Strepsiptera. http://rameau.snv.jussieu. fr/cgi-bin/strepsiptera.pl?lang=en (last accessed on 26 August 2012).

Kathirithamby J. \& Moya-Raygoza G. 2000: Halictophagus naulti sp. n. (Strepsiptera: Halictophagidae), a new species parasitic in the corn leafhopper (Homoptera: Cicadellidae) from Mexico. - Ann. Entomol. Soc. Am. 93: 1039-1044.

Kifune T. \& HiRashima Y. 1989: Taxonomic studies on the Strepsiptera in the collection of the Bishop Museum (Notulae Strepsipterologicae XX). - Esakia 28: 11-48.

Melichar L. 1914: Monographie der Tropiduchinen (Homoptera). - Verh. Naturforsch. Vereins Brünn 53: 1-145.

Metcalf Z.P. 1954: General Catalogue of the Homoptera. Fasc. IV. Fulgoroidea. Part 11. Tropiduchidae. North Carolina State College, Raleigh, NC, $167 \mathrm{pp}$.

MuIR F. 1931: Descriptions and records of Fulgoroidea from Australia and the South Pacific Islands, No. I. - Rec. Aust. Mus. 18: 63-83.

SCHILTHIUZEN M. 2007: The evolution of chirally dimorphic insect genitalia. - Tijdschr. Entomol. 150: 347-354.

Wang R.R., Liang A.P. \& WebB M.D. 2009: A new tropiduchid planthopper genus and species from China with descriptions of in copula genitalic structures (Hemiptera: Fulgoromorpha). - Syst. Entomol. 34: 434-442.

Wilson M.R. \& MALENOvsKÝ I. 2007: Tropiduchidae described by Leopold Melichar (Hemiptera, Fulgoromorpha). - Acta Mus. Morav. (Sci. Biol.) 92: 137-153.

Received May 4, 2012; revised and accepted October 29, 2012 